\title{
Bone Densitometry Measurement for Early Breast Cancer Patients
}

\author{
R.A.M. Rizk, H.K.Hamdi", Khaled Ammer ${ }^{* *}$, M.M. Emam **** \\ and A.I.Thabet ${ }^{* * * * *}$. \\ Physics Dept., Faculty of Science, Hilwan University, \\ ** Oncology Dept., El-Hussein University Hospital, Al-Azhar \\ University, ${ }^{* *}$ Rheumatology Dept., Sayed Galal Hospital Al- \\ Azhar University, ${ }^{* * *}$ Physics Dept., Faculty of Sciences Al- \\ Azhar University, Cairo and ${ }^{* * * *}$ Medical Sciences Dept., \\ Radiological Imaging Technology Applied to Medical Science, \\ Misr University for Science \& Technology (MUST), $6^{\text {th }}$ of \\ October city, Egypt.
}

OMEN with breast cancer particularly individuals diagnosed at
a relatively early age have an increased occurrence of
osteoporosis. Aim of present work is to apply Dual Energy X-ray
Absorptiometry (DEXA) technique on breast cancer patients who
undergoing chemotherapy treatment for monitoring bone health and
occurrence of osteoporosis. DEXA is considered as the most common
and accurate way, to perform the Bone Mineral Area Density
(BMAD) scanning.

DEXA scan for Lumbar Spine (LS) and Total Hip (TH) have been done in the present study for two age groups of women. First group ranged from 25 to 36 years old and second one ranged from 41 to 47 years old. All diagnosed women by any disease affects bone metabolism or classified as a osteoporosis patient have been excluded, in the beginning, of this study and the DEXA scan was completed for each participant at 0-month (baseline; controlled patients), 6-months and 12-months in order to record the effect of chemotherapy treatment.

For both groups, after 6-months a reduction of LS-BMAD and THBMAD baselines values have been detected; LS-BMAD reduced significantly from $1.186 \mathrm{~g} / \mathrm{cm}^{2} \pm 0.083$ to $1.143 \mathrm{~g} / \mathrm{cm}^{2} \pm 0.083$, and TH-BMAD reduced significantly from $1.003 \mathrm{~g} / \mathrm{cm}^{2} \pm 0.028$ to 0.975 $\mathrm{g} / \mathrm{cm}^{2} \pm 0.028$. After twelve months, BMAD values of LS and TH were $1.125 \mathrm{~g} / \mathrm{cm}^{2} \pm 0.018,0.969 \mathrm{~g} / \mathrm{cm}^{2} \pm 0.006$, respectively.

The present study took place over twelve months and demonstrates that adjuvant systemic chemotherapy has deleterious effect on BMAD in pre-menopausal women with early breast cancer; also a great effect of age on BMAD has been revealed.

Keywords: Breast cancer, Osteoporosis, Bone mineral area density (BMAD), Dual energy X-ray absorptiometry (DEXA). 
Breast cancer is the most common cancer among women and the leading cause of death in women, aged $35-54$ years ${ }^{(1)}$. Although the median age for breast cancer is over 60 years, around $25 \%$ of the women are below 50 years of age at the time of diagnosis ${ }^{(2)}$. World-wide, it is estimated that more than 1 million women are diagnosed with breast cancer every year and more than 410,000 of them will die from this disease ${ }^{(3)}$.

Most early-stage breast cancer patient are offered chemotherapy, the nature of which varies according to many clinical and pathological variables like disease stage and axillary lymph node status ${ }^{(4)}$. Adjuvant therapies shown survival improve of non-metastatic breast cancer (NMBC) patients, but they also decrease bone mineral density (BMAD) ${ }^{(5)}$.

Guidelines from the recent National Institutes of Health Consensus Development Conference on Adjuvant Treatment and the National Comprehensive Cancer Network recommend adjuvant chemotherapy for invasive breast cancer tumors greater than $1 \mathrm{~cm}$, irrespective of the axillary nodal status ${ }^{(6,7)}$. One of the most common side effects of adjuvant chemotherapy is primary ovarian failure ${ }^{(6-8)}$, premenopausal patient commonly induces a sudden deterioration in estrogen production and often an early menopause ${ }^{(9)}$. These patients often experience menopause, either temporary or permanent ${ }^{(10)}$, which is associated with a higher rate of bone loss than bone formation ${ }^{(10,11)}$.

Most women are likely to be long-term survivors after breast cancer diagnosis, it is of vital importance to maintain bone health during and after anticancer treatments that affect the skeleton ${ }^{(12)}$. Small prospective studies have shown that bone loss ranges from 3\% to $8 \%$ in the lumbar spine (LS) and $2 \%$ to $4 \%$ in the total hip $(\mathrm{TH})$, with higher rates in those who develop amenorrhea ${ }^{(10-13)}$. Bone metabolism is highly affected by changes in ovarian function. After the onset of menopause, decrease in estrogen levels is associated with loss of bone and early menopause is one of the strongest predictors of osteoporosis. Estrogen-sensitive changes in BMAD are most rapidly seen in the lumbar spine and the hip, where osteoporotic fractures also are frequent ${ }^{(14)}$.

Data from the Women's Health Initiative Observational Study reported that postmenopausal survivors of breast cancer have a $15 \%$ higher fracture risk than women without a history of breast cancer ${ }^{(15)}$.

Dual-energy X-ray absorptiometry (DXA, previously DEXA) is a means of measuring bone mineral density. Two X-ray beams with different energy levels are aimed at the patient's bones. When soft tissue absorption is subtracted out the BMAD can be determined through the absorption of each beam by bone. Dual-energy X-ray absorptiometry is the most widely used and most thoroughly studied bone density measurement technology.

The DXA scan is typically used to diagnose and follow osteoporosis, as contrasted to the nuclear bone scan, which is sensitive to certain metabolic Egypt. J. Biophys. Biomed. Engng. Vol. 13 (2012) 
diseases of bones in which bones are attempting to heal from infections, fractures, or tumors.

BMAD is measured by dual-energy X-ray absorptiometry (DEXA) to identify woman with low BMAD or osteoporosis at high risk of fracture ${ }^{(3,12)}$.

\section{Materials and Methods}

Convenience sample of 20 premenopausal women with early non-metastatic breast cancer awaiting treatment with adjuvant chemotherapy was divided into two groups; first group (gp1) 10 patients, ranged from 25 to 36 years old and second group (gp2) 10 patients, ranged from 41 to 47 years old.

Any woman passed through this scan has signed informed consent and all women with a history of metabolic bone disease, hyperparathyroidism, Paget's disease rheumatoid arthritis, ankylosing spondylitis and newly diagnosed hyperthyroidism were excluded for the effect of these conditions on bone metabolism.

BMAD of lumbar spine and hip joint using dual-energy x-ray absorptiometry (DEXA) were performed at baseline (month 0) and then start of treatment of breast cancer by giving the patient doses of chemotherapy. The DEXA examination repeated after 6 months (month 6), then resumption of chemotherapy for a further period of 6 months has been achieved. Finally, the DEXA examination was applied again (month 12) and the data collected for analysis; the analysis of decline in BMAD mean at the Lumber Spin and Total Hip during the research period is illustrated in the next section.

\section{Results}

Data were presented on a total of 20 women who were treated with chemotherapy. The mean patient age was 36.95 with SD 7.16 (range, 25-47) years; $50 \%$ of patients (range, 25-36) years and others (range, 41-47) years.

Data analysis of Tables 1 and 2 reveals that, the Baseline lumbar spine and total hip BMAD for most of patients was greater than in DEXA scanner reference population $(\mathrm{T} \text { score })^{(1)}$ Some cases were in border line and there is a relationship between baseline BMAD and age. The mean baseline lumbar spine BMAD was $\left(1.251 \mathrm{~g} / \mathrm{cm}^{2}\right.$ with $\mathrm{T}$ score 0.43 ) for patients (range, $\left.25-36\right)$ years, while the mean BMAD was $\left(1.121 \mathrm{~g} / \mathrm{cm}^{2}\right.$ with T score -0.68 ) for patients (range, 41-47) years.

${ }^{x}$ The T-score on your bone density report shows how much your bone mass vary or deviates from the bone mass of an average healthy 30 year old adult. Bone density is like any other medical test or measurement. A T-score is a standard deviation -- a mathematical term that calculates how much a result varies from the mean. The score that you will receive from your bone mineral density (BMAD or DXA) test is measured as a standard deviation from the mean. 
Mean total hip BMAD was $\left(1.054 \mathrm{~g} / \mathrm{cm}^{2}\right.$ with $\mathrm{T}$ score 0.42$)$ for patients (range, 25-36) years, while the mean BMAD was $\left(0.951 \mathrm{~g} / \mathrm{cm}^{2}\right.$ with T score 0.41 ) for patients (range, 41-47) years. For all group of age the mean BMAD was $\left(1.186 \mathrm{~g} / \mathrm{cm}^{2}\right.$ with $\mathrm{T}$ score -0.25$)$ for lumbar spine and the mean BMAD was $\left(1.003 \mathrm{~g} / \mathrm{cm}^{2}\right.$ with $\mathrm{T}$ score 0.01$)$ for total hip.

TABLE 1. BMAD values for both age groups at Controlled patients at 0-month.

\begin{tabular}{|l|c|c|c|c|c|}
\hline \multirow{2}{*}{ No. } & \multirow{2}{*}{ Age } & \multicolumn{5}{|c|}{ Base line } \\
\cline { 3 - 6 } & & \multicolumn{2}{|c|}{ L.S } & \multicolumn{2}{c|}{ T.H } \\
\cline { 3 - 6 } & & T.score & BMAD & T.score & BMAD \\
\hline 1. & $25 \mathrm{y}$ & 1.5 & 1.379 & 4.0 & 1.534 \\
\hline 2. & $27 \mathrm{y}$ & 0.4 & 1.246 & -0.1 & 0.984 \\
\hline 3. & $29 \mathrm{y}$ & 0.5 & 1.258 & 0.8 & 1.086 \\
\hline 4. & $30 \mathrm{y}$ & 0.1 & 1.207 & -0.1 & 0.984 \\
\hline 5. & $30 \mathrm{y}$ & 1.1 & 1.333 & -0.4 & 0.957 \\
\hline 6. & $31 \mathrm{y}$ & 0.4 & 1.253 & 1.1 & 1.130 \\
\hline 7. & $31 \mathrm{y}$ & 0.7 & 1.284 & 0.4 & 1.044 \\
\hline 8. & $31 \mathrm{y}$ & 0.0 & 1.201 & 0.1 & 1.013 \\
\hline 9. & $32 \mathrm{y}$ & -0.2 & 1.173 & -0.9 & 0.897 \\
\hline 10. & $36 \mathrm{y}$ & -0.2 & 1.173 & -0.7 & 0.913 \\
\hline 11. & $41 \mathrm{y}$ & -0.7 & 1.122 & 0.1 & 1.013 \\
\hline 12. & $42 \mathrm{y}$ & -0.1 & 1.192 & -0.9 & 0.890 \\
\hline 13. & $42 \mathrm{y}$ & -0.7 & 1.121 & 0.2 & 1.028 \\
\hline 14. & $43 \mathrm{y}$ & -0.9 & 1.089 & -0.4 & 0.947 \\
\hline 15. & $43 \mathrm{y}$ & -0.3 & 1.169 & -0.2 & 0.977 \\
\hline 16. & $44 \mathrm{y}$ & -1 & 1.085 & -0.2 & 0.972 \\
\hline 17. & $44 \mathrm{y}$ & -1 & 1.085 & -0.4 & 0.948 \\
\hline 18. & $44 \mathrm{y}$ & -0.2 & 1.175 & -0.8 & 0.905 \\
\hline 19. & $47 \mathrm{y}$ & -0.9 & 1.087 & -0.8 & 0.906 \\
\hline 20. & $47 \mathrm{y}$ & -1 & 1.084 & -0.7 & 0.896 \\
\hline & & & & & \\
\hline
\end{tabular}

TABLE 2. Patient Demographics and Baseline Disease Characteristics .

\begin{tabular}{|l|l|c|c|}
\hline \multirow{5}{*}{ Position } & \multicolumn{1}{|c|}{ Characteristics } & $\begin{array}{c}\text { Mean } \\
\text { density } \\
\text { g/cm }\end{array}$ & SD \\
\hline \multirow{5}{*}{ Lumbar Spine (LS) } & \multicolumn{1}{|c|}{} & \\
& BMAD g/cm ${ }^{2}$ (Both groups) & 1.186 & \pm 0.09 \\
& Age (25-36) & 1.251 & \pm 0.095 \\
\cline { 2 - 4 } & Age (41-47) & 1.121 & \pm 0.085 \\
\cline { 2 - 4 } & Agcore (Both groups) & -0.25 & \pm 0.705 \\
& Age (41-47) & 0.43 & \pm 0.859 \\
& BMAD g/cm ${ }^{2}$ (Both groups) & -0.68 & \pm 0.129 \\
\hline & Age (25-36) & 1.003 & \pm 0.252 \\
& Age (41-47) & 1.054 & \pm 0.349 \\
\cline { 2 - 4 } & T.score (Both groups) & 0.951 & \pm 0.071 \\
\hline & Age (25-36) & 0.01 & \pm 1.062 \\
& Age (41-47) & 0.42 & \pm 1.393 \\
& & -0.41 & \pm 0.558 \\
\hline
\end{tabular}

Egypt. J. Biophys. Biomed. Engng. Vol. 13 (2012) 
Figure $1(\mathrm{~A}, \mathrm{~B})$ parts show that there is decline in total hip and lumbar spine BMAD for all age group after starting chemotherapy in first and second six month and also show that the decline in lumbar spine in the second six month is greater than in total hip.

Table 3 and Fig. 1 (C, D) parts, reveal that lumbar spine BMAD mean decline significantly on those patients (range, 25-36) years in the first 6 months only from $\left(1.251 \mathrm{~g} / \mathrm{cm}^{2} \pm 0.035\right.$ to $1.216 \pm 0.035 \mathrm{~g} / \mathrm{cm}^{2}$ ) with (T-score 0.43 to 0.13 ). A small change happen in next 6 months $\left(1.216 \mathrm{~g} / \mathrm{cm}^{2} \pm 0.006\right.$ to $1.21 \mathrm{~g} / \mathrm{cm}^{2} \pm$ 0.006 ) with (T-score 0.13 to 0.02 ) while for those patients who (range, 41-47) years the Lumbar spine BMAD decline significantly over both the first and after second six month's period from $\left(1.121 \mathrm{~g} / \mathrm{cm}^{2} \pm 0.051\right.$ to $\left.1.0702 \mathrm{~g} / \mathrm{cm}^{2} \pm 0.051\right)$ with (T-score- 0.68 to -1.11) for the first six months. The change in second 6 months was very small it range from $\left(1.0702 \mathrm{~g} / \mathrm{cm}^{2} \pm 0.036\right.$ to $1.043 \mathrm{~g} / \mathrm{cm}^{2} \pm$ 0.036) with (T-score -1.11 to -1.4 ).

TABLE 3. L.S BMAD values for both age groups at 6, 12 months.

\begin{tabular}{|c|c|c|c|c|c|}
\hline \multirow{2}{*}{ No. } & \multirow{2}{*}{ Age } & \multicolumn{4}{|c|}{ L.S } \\
\cline { 3 - 6 } & & \multicolumn{2}{|c|}{ 6 months } & \multicolumn{2}{c|}{ 12 months } \\
\cline { 3 - 6 } & & T.score & BMAD & T.score & BMAD \\
\hline 1. & $25 \mathrm{y}$ & 1.3 & 1.354 & 1.3 & 1.354 \\
\hline 2. & $27 \mathrm{y}$ & 0.3 & 1.239 & 0.3 & 1.239 \\
\hline 3. & $29 \mathrm{y}$ & 0.2 & 1.226 & 0.2 & 1.226 \\
\hline 4. & $30 \mathrm{y}$ & -0.2 & 1.172 & -0.2 & 1.172 \\
\hline 5. & $30 \mathrm{y}$ & 1 & 1.321 & 1 & 1.321 \\
\hline 6. & $31 \mathrm{y}$ & 0.2 & 1.228 & 0.1 & 1.218 \\
\hline 7. & $31 \mathrm{y}$ & 0.4 & 1.250 & 0.3 & 1.231 \\
\hline 8. & $31 \mathrm{y}$ & -0.5 & 1.141 & -0.6 & 1.129 \\
\hline 9. & $32 \mathrm{y}$ & -0.6 & 1.126 & -0.7 & 1.115 \\
\hline 10. & $36 \mathrm{y}$ & -0.8 & 1.101 & -0.9 & 1.089 \\
\hline 11. & $41 \mathrm{y}$ & -1 & 1.085 & -1.1 & 1.073 \\
\hline 12. & $42 \mathrm{y}$ & -0.4 & 1.149 & -1.5 & 1.025 \\
\hline 13. & $42 \mathrm{y}$ & -1 & 1.085 & -1.1 & 1.073 \\
\hline 14. & $43 \mathrm{y}$ & -1 & 1.085 & -1.2 & 1.052 \\
\hline 15. & $43 \mathrm{y}$ & -1.1 & 1.073 & -1.3 & 1.042 \\
\hline 16. & $44 \mathrm{y}$ & -1.5 & 1.025 & -1.7 & 1.001 \\
\hline 17. & $44 \mathrm{y}$ & -1.3 & 1.041 & -1.5 & 1.025 \\
\hline 18. & $44 \mathrm{y}$ & -0.7 & 1.121 & -0.9 & 1.086 \\
\hline 19. & $47 \mathrm{y}$ & -1.5 & 1.025 & -1.8 & 0.987 \\
\hline 20. & $47 \mathrm{y}$ & -1.6 & 1.013 & -1.9 & 0.975 \\
\hline & & & & & \\
\hline
\end{tabular}


Figure 1 (E, F) shows that a small decline of Total hip BMAD mean of those patients (range, 25-36) years in the first 6 months only versus baseline from $\left(1.054 \mathrm{~g} / \mathrm{cm}^{2} \pm 0.025\right.$ to $\left.1.029 \mathrm{~g} / \mathrm{cm}^{2} \pm 0.025\right)$ and with $(\mathrm{T}$ score) with Table 4 and Fig. 1 (E, F) parts, reveal that a small decline of total Hip BMAD mean of those patients (range, 25-36) years in the first 6 months only versus baseline from $\left(1.054 \mathrm{~g} / \mathrm{cm}^{2} \pm 0.025\right.$ to $1.029 \mathrm{~g} / \mathrm{cm}^{2} \pm$ 0.025 ) with (T-score 0.42 to 0.16 ). For those patients (range, 41-47) years the total hip BMAD mean decline significantly over both the first and second six months period from $\left(0.951 \mathrm{~g} / \mathrm{cm}^{2} \pm 0.031\right.$ to $\left.0.92 \mathrm{~g} / \mathrm{cm}^{2} \pm 0.031\right)$ with (T-score -0.41 to -0.71$)$. In the second 6 months the change was $(0.92$ $\mathrm{g} / \mathrm{cm}^{2} \pm 0.011$ to $0.909 \mathrm{~g} / \mathrm{cm}^{2} \pm 0.011$ ) with (T-score -0.71 to -0.81 ).

TABLE 4. T.H BMAD values for both age groups at 6,12 months.

\begin{tabular}{|c|c|c|c|c|c|}
\hline \multirow{3}{*}{ No. } & \multirow{3}{*}{ Age } & \multicolumn{4}{|c|}{ T.H } \\
\hline & & \multicolumn{2}{|c|}{6 months } & \multicolumn{2}{|c|}{12 months } \\
\hline & & T.score & BMAD & T.score & BMAD \\
\hline 1. & $25 \mathrm{y}$ & 3.8 & 1.515 & 3.8 & 1.515 \\
\hline 2. & $27 \mathrm{y}$ & -0.3 & 0.963 & -0.3 & 0.963 \\
\hline 3. & $29 y$ & 0.6 & 1.064 & 0.6 & 1.064 \\
\hline 4. & $30 y$ & -0.4 & 0.955 & -0.4 & 0.955 \\
\hline 5. & $30 y$ & -0.7 & 0.927 & -0.7 & 0.927 \\
\hline 6. & $31 \mathrm{y}$ & 0.7 & 1.093 & 0.7 & 1.093 \\
\hline 7. & $31 \mathrm{y}$ & 0.1 & 1.025 & 0.1 & 1.025 \\
\hline 8. & $31 \mathrm{y}$ & -0.2 & 0.986 & -0.2 & 0.986 \\
\hline 9. & $32 \mathrm{y}$ & -1 & 0.874 & -1 & 0.874 \\
\hline 10. & $36 y$ & -1 & 0.885 & -1 & 0.885 \\
\hline 11. & $41 \mathrm{y}$ & -0.1 & 0.998 & -0.1 & 0.997 \\
\hline 12. & $42 y$ & -1.1 & 0.894 & -1.2 & 0.864 \\
\hline 13. & $42 y$ & -0.1 & 0.998 & -0.1 & 0.998 \\
\hline 14. & $43 y$ & -0.7 & 0.911 & -0.8 & 0.905 \\
\hline 15. & $43 y$ & -0.5 & 0.938 & -0.6 & 0.929 \\
\hline 16. & $44 \mathrm{y}$ & -0.4 & 0.948 & -0.5 & 0.938 \\
\hline 17. & $44 \mathrm{y}$ & -0.7 & 0.913 & -0.8 & 0.904 \\
\hline 18. & $44 \mathrm{y}$ & -1.1 & 0.874 & -1.2 & 0.866 \\
\hline 19. & $47 \mathrm{y}$ & -1.2 & 0.865 & -1.4 & 0.845 \\
\hline 20. & $47 y$ & -1.2 & 0.864 & -1.4 & 0.846 \\
\hline
\end{tabular}




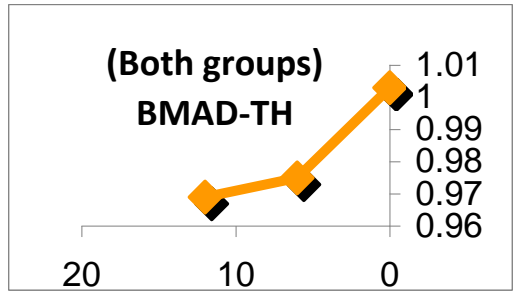

(A)

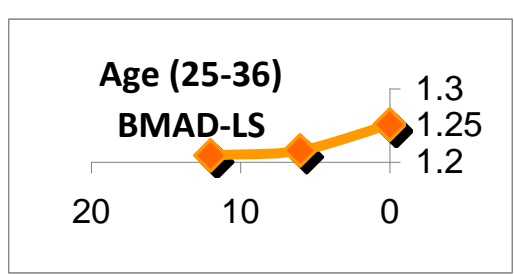

(C)

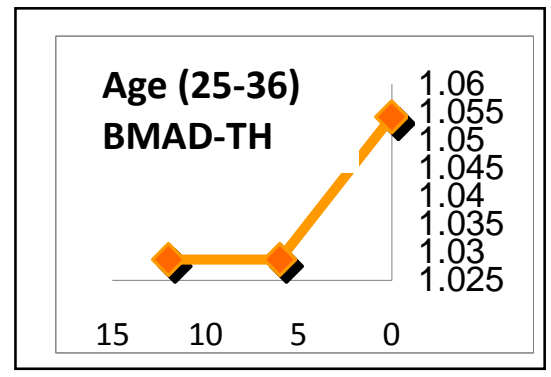

(E)

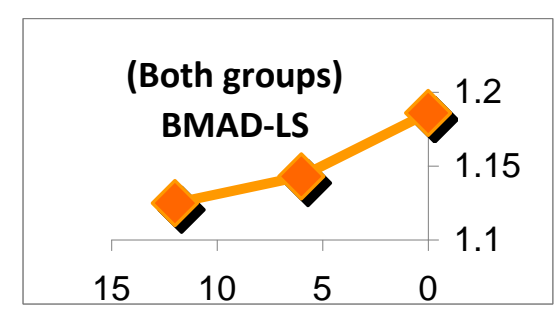

(B)

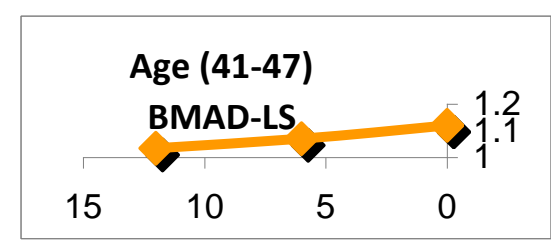

(D)

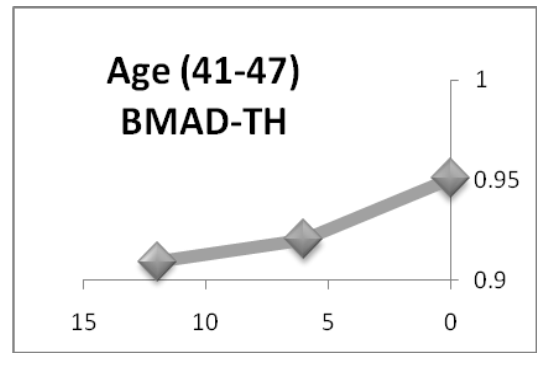

(F)

Fig. 1. Mean lumbar spine and total hip BMAD in $(0,6,12)$ months.
A) Mean TH BMAD for both groups.
B) Mean LS BMAD for both groups.
C) Mean LS BMAD for group (1).
D) Mean LS BMAD for group (2).
E) Mean TH BMAD for group (1)
F) Mean TH BMAD for group (2).

\section{Discussion}

The increased fracture risk associated with treatment-related loss of bone mineral density is an increasingly important problem for women diagnosed with breast cancer. In premenopausal patients, chemotherapy induced ovarian failure and adjuvant ovarian suppression/ablation can lead to rapid and profound loss of bone mineral density ${ }^{(16)}$. 
There was relationship between baseline BMAD and age. The mean baseline lumbar spine BMAD declines significantly in the first six months but there with a small rate in the next six months for patients who range from $(25-36)$ years old. The noticed change for $1^{\text {st }}$ group is less than on those patients who ranged from (41- 47) years old, $2^{\text {nd }}$ group, which its mean baseline lumbar spine BMAD declines significantly in first six months more than in the second six months. The mean baseline total hip BMAD declines significantly only in the first six months for those patients who ranged from $(25-36)$ years old and less than for those patients who ranged from (41- 47) years old.

For patients who ranged from (41-47) years the decline took place in both first and the second six months but the decline in first six months is more significantly appeared. While Richard L. Theriault investigating their strategy of preventing chemotherapy-induced bone loss in women with breast cancer they discovered that, although many women receiving adjuvant therapy will experience amenorrhea, it is more likely to be transient in younger women. So the obtained result of our study can be referred to that, women ranged from (4147) years old is near from menopause and the age is a predominant factor in the development of permanent ovarian failure; $20 \%-40 \%$ incidence for women $<40$ years of age and a $70 \%-90 \%$ incidence for women $\geq 40$ years of age ${ }^{(17)}$.

Baseline lumbar spine and total hip BMAD for most of patients was greater than in DEXA scanner reference population ( $T$ score -1 ) but some cases was in border line. This explains why some cases suffering from osteopenia and other cases not and this interpretation supported by Richard L. Theriault and Shapiro et al., studies which revealed that according to the existence of a $4 \%$ reduction in BMAD within 6 months of breast cancer treatment, breast cancer itself tends to promote osteoclast activity, putting patients at increased risk of osteopenia and osteoporosis $^{(17)}$.

Our study reveals that there is decline in lumbar spine and hip BMAD In premenopausal women induced by adjuvant chemotherapy occurs independently of the effect of that therapy on ovarian function.

There is a reduction of BMAD during the first six months in both lumbar spine and lumbar hip for the two age groups during the first six month the reduction of BMAD for the lumbar spine and total hip was $1.186 \mathrm{~g} / \mathrm{cm}^{2} \pm 0.083$ to $1.143 \mathrm{~g} / \mathrm{cm}^{2} \pm 0.083,1.003 \pm \mathrm{g} / \mathrm{cm}^{2} 0.028$ to $0.975 \mathrm{~g} / \mathrm{cm}^{2} \pm 0.028$ respectively, this goes step by step by study done on women who experience chemotherapy induced ovarian failure which showed those develop rapid and highly significant decreases in BMAD in the spine and femur that are detectable within 6 months of starting chemotherapy.

In contrast, women who retained menstrual function had non-significant decreases in BMAD at these sites ${ }^{(6)}$.

Egypt. J. Biophys. Biomed. Engng. Vol. 13 (2012) 
Although there is a very small change happen in the next 6 month in both of age group the decline appears in patients ranged from $(25-36)$ less than patients ranged (41-47) in total hip BMAD our study shows that the decline happen in both age group in the first six months but the change happen only in patients ranged from (41-47) in next six months this changes may be interpreted by patients over 40 are closer to their natural menopausal age so ovarian failure developed after a shorter duration of chemotherapy.

\section{Conclusion}

It is now clear that women with breast cancer have an increased fracture risk compared with age matched woman without breast cancer; our study demonstrates that adjuvant systemic chemotherapy has deleterious effect on BMAD in pre-menopausal women with early breast cancer.

The lumbar spine and total hip BMAD in both two age groups in first six month were declined but this decline was in age group $(25-36)$ is less than the other age group and in second six month the decline happen mainly in patients range from (41-47 years) in both lumbar spine and total hip which revealed the great effect of age on BMAD.

\section{References}

1. Storm, H.H., Engholm, G., Hakulinen, T., et al., Survival of patients diagnosed with cancer in the Nordic countries up to 1999-2003 followed to the end of 2006. A critical overview of the results. Acta Oncol. 49 (5), 532-44 (2010).

2. Sverrisdottir, A., Adjuvant tamoxifen and luteinizing hormone-releasing hormone agonists in premenopausal breast cancer on long-term benefits and side effects in a randomised study (Stockholm). Department of oncology-pathology Karolinska Institutet. (2012).

3. Kalder, M., Ja“ ger, C., et al., Breast cancer and bone mineral density: The marburg breast cancer and osteoporosis trial (MABOT II). Climacteric. 14, 352-361 (2011).

4. Abdel-Razeq, Hikmat and Awidi, A. Bone health in breast cancer survivors. Journal of Cancer Research and Therapeutics, 7, 3 (2011).

5. Alonso, B. , Aleman, R., Rodríguez, L. et al., Bone mineral density in women with non-metastatic breast cancer: Effect of intravenous bisphosphonates given before adjuvant therapies. Journal of Clinical Oncology. 25 (18s), (2007).

6. Shapiro, Charles, L., Manola, J. and Leboff, M. ovarian failure after adjuvant chemotherapy is associated with rapid bone loss in women with early breast cancer. Journal of Clinical Oncology. 19 (14), 3306-3311 (2001).

7. Adjuvant Therapy for Breast Cancer, NIH consensus statement, 17 (4), 1-23 (2000). 
8. Abdel-Raziq, H. and Awidi, A., Bone health in breast cancer survivors, Journal of cacer research and therapeutics, 7, 3 (2011).

9. Laster, J. and Coleman, R., Bone, loss and the aromatase inhibitors. britich Jornal of Cancer, 9, 3 (2005).

10. Dawn, L., Hershman, Donald, J. McMahon and Crew, Katherine, D. et al., Zoledronic acid prevents bone loss in premenopausal women undergoing adjuvant chemotherapy for early-stage breast cancer. Journal of Clinical Oncology, 26, 29 (2008).

11. Maxewell,C. and Viale, P. Hallquist, Cancer Treatment - induced bone loss in patient with breast or prostate cancer. Oncology Nursing Forum, 32, 3 (2005).

12. Reid, D.M., Doughty, J., Eastell, R., Heys, S.D. and Howell, A. et al., Guidance for the management of breast cancer treatment-induced bone loss: A consensus position statement from a UK Expert Group. Cancer Treat Rev. 3, 4 (2008).

13. Fuleihan, Gel-H., Salamoun, M. and Mourad, Y.A., et al., Pamidronate in the prevention of chemotherapyinduced bone loss in premenopausal women with breast cancer: A randomized controlled trial. J. Clin. Endocrinol. Metab. 9, 3209-3214 (2005).

14. Sverrisdo'ttir, A., Fornander, T. and Jacobsson, H. et al., Bone mineral density among premenopausal women with early breast cancer in a randomized trial of adjuvant endocrine therapy. Journal of clinical oncology, 22, 18 (2004).

15. Chen, Z., Maricic, M. and Bassford, T.L., et al., Fracture risk among breast cancer survivors: Results from the women's health initiative observational study. Arch Intern Med. 165, 552-558 (2005).

16. Gralow, J. R, Bone density in breast cancer: when to intervene?. Journal of clinical oncology. 25, 22 (2007).

17. Theriault R. L., Strategies to prevent chemotherapy-induced bone loss in women with breast cancer. Clinical Breast Cancer, 5 (2), S63-S70 (2005).

(Received 29/10/2013; accepted $25 / 3 / 2014$ ) 


\section{متابعة قياس الكثافة المساحية للعظام عند الاصابة المبكرة بسرطان}

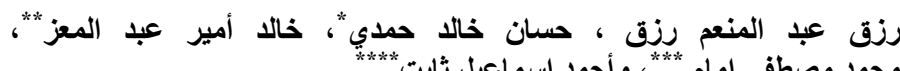

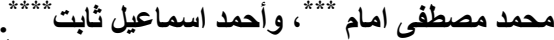

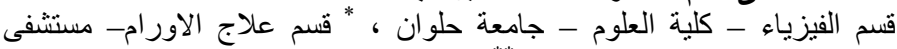

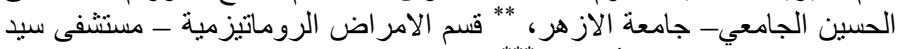

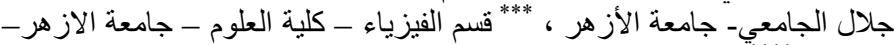

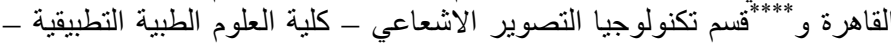

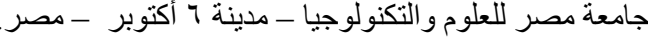

النساء المصابات بسرطان الثذي لاسيما من تم تشخيصهن في عمر مبكر نسبيا

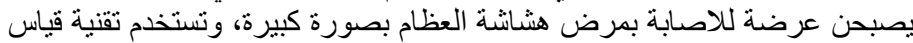
شعة الطاقة السينية الثنائية (DEXA) في تحديد درجة سلامة العظام وتقييم مستوى

الهشاشة.

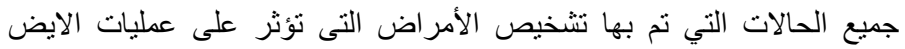

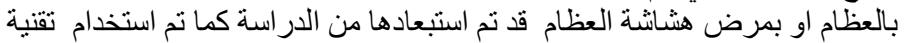

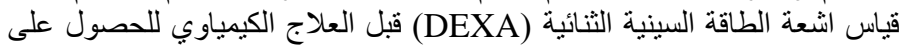

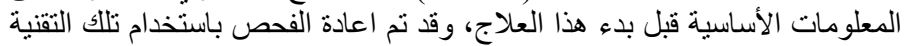

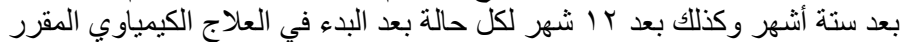

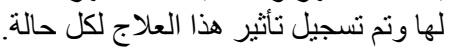

أظهرت الدراسة حدوث انخفاض في كثافة العظام لجميع الفئات العمرية للفئتين

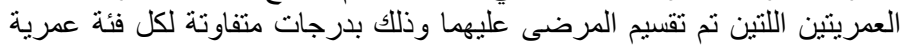

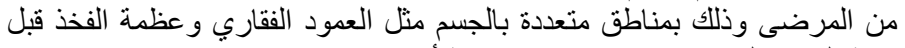

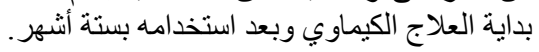

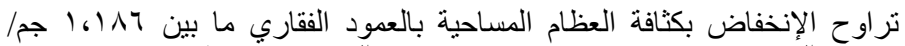

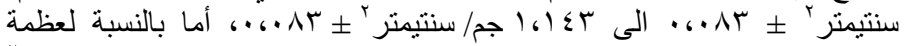

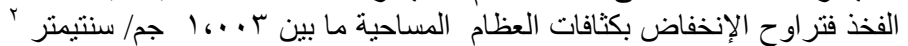
الكي

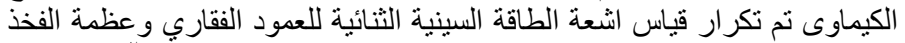

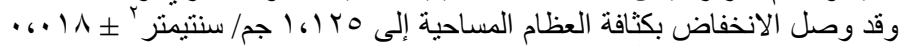

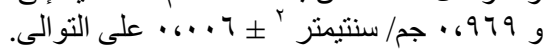

